\title{
IgM rheumatoid factor removal and performance of the FTA-ABS (IgM) test in congenital
} syphilis

\author{
M P Meyer, D Roditi, S Louw
}

\begin{abstract}
Objective-To determine the performance of the FTA-ABS (IgM) test in congenital syphilis after eliminating interference by IgM rheumatoid factor (RF) and preventing competitive inhibition by IgG.
\end{abstract}

Design-The FTA-ABS (IgM) test was carried out before and after RF removal (achieved by immunoprecipitation of the IgG) in infants with congenital syphilis and controls.

Setting-Newborns delivered in the Peninsula Maternal and Neonatal Services in Cape Town and infants presenting at Red Cross War Memorial Children's Hospital.

Subjects-Infants with congenital syphilis aged $0-4$ months were divided into those with clinical signs at presentation and those who were asymptomatic at delivery. In addition, patients without congenital syphilis but with similar clinical signs at presentation were investigated as were control infants.

Outcome measure-The diagnosis of congenital syphilis was based on the criteria suggested by Kaufman et al (1977).

Results-Amongst symptomatic infants with congenital syphilis the FTA-ABS (IgM) test was positive in $34(92 \%)$ of 37 cases prior to abolishing the $R F$ effect and in $29(78.4 \%)$ of 37 cases afterwards $(p=0 \cdot 19)$. In 12 cases of congenital syphilis who were asymptomatic at birth, 10 had positive FTA-ABS (IgM) tests before RF removal and only three had positive tests afterwards $(p=0.006)$. False positive tests were not found amongst 15 symptomatic infants whose clinical features mimicked those of the infants with congenital syphilis. Among 51 healthy infants the test had a false-positive rate of $2 \%$ in newborns and $13 \%$ in older infants. The false positive reactions were eradicated by IgG precipitation.

Conclusions-Following IgG and RF removal there was an improvement in the specificity of the FTA-ABS (IgM) test but this was at the expense of a loss of sensitivity, particularly in asymptomatic newborns. For newborns, if the FTA-ABS (IgM) test was positive, the patient was likely to require treatment for congenital syphilis, regardless of whether the result was due to the presence of RF or specific IgM.

\section{Introduction}

Although congenital syphilis is not uncommon, especially in developing countries, its diagnosis remains difficult. ${ }^{12}$ A combination of epidemiological, clinical and serological evidence is usually necessary before the diagnosis can be entertained with any degree of certainty. ${ }^{3}$

The serological tests are complicated by the transfer of anti-treponemal IgG antibody from the mother to the fetus. As 19S IgM does not normally cross the placenta, a fluorescent treponemal antibody absorption IgM test (FTA-ABS (IgM)) was developed to identify infected infants. ${ }^{4}$ Unfortunately, the test suffers from false positive as well as false negative results. The former are said to occur in approximately $10 \%$ of cases while a falsely negative test is initially found in up to $35 \%$ of cases with delayed onset disease.

Rheumatoid factor (RF), usually an IgM directed against IgG, is a cause of false positive results. ${ }^{6}$ The mechanism of this reaction is that anti-treponemal IgG binds to spirochaetal antigens. IgM RF then attaches to the bound IgG and is falsely identified as antigen-specific IgM.

IgM RF is present in over $90 \%$ of infants with congenital syphilis and is also found in other congenital infections like those caused by cytomegalovirus (CMV) and rubella. ${ }^{6-9}$

Removal of all the RF to improve the specificity of the FTA-ABS (IgM) test may be difficult but RF interference can be eliminated by removing IgG from serum. ${ }^{10}$ IgG removal may also improve sensitivity of testing for $\operatorname{IgM}$ antibodies, as has been shown with a Treponema pallidum IgM enzyme linked immunosorbent assay (ELISA) in adult patients with syphilis. ${ }^{11}$ Removal of the IgG probably reduces competitive inhibition between IgG and IgM antibodies for antigen binding sites.

Our aim was to determine the performance of the FTA-ABS (IgM) test in congenital syphilis, after eliminating RF interference and preventing competitive inhibition by IgG.

\section{Materials and methods}

Patient selection

The infants with congenital syphilis fulfilled established clinical and serological criteria. ${ }^{12}$ Treatment with procaine penicillin was commenced as soon as the diagnosis became apparent. Informed consent was obtained from the parents and the study was approved by the Ethics and Research Committee of the University of Cape Town. The four groups of patients considered were: 
Group 1: Infants having congenital syphilis with clinical signs at presentation: These patients presented to the Peninsula Maternal and Neonatal Service or the Red Cross War Memorial Children's Hospital over an 18 month period and were aged 0-4 months. There were 37 babies in this category, 22 of whom presented in the first few days of life and 15 who presented between the ages of 2 weeks and 4 months.

Group 2: Infants with congenital syphilis without clinical signs at birth: The 12 patients in this group were asymptomatic at birth. Eleven of the cases have been the subject of a previous report. ${ }^{13}$ The infants were investigated and followed-up because of a maternal history of untreated or inadequately treated syphilis. In four instances radiological investigation carried out at birth revealed abnormalities of the long bones-there were no other features of disease. These four cases were fully treated in the perinatal period. In the remaining eight cases congenital syphilis became apparent at followup. The infants were seen at 6 weeks and again at 3-4 months after birth. A clinical examination was performed and blood was drawn for VDRL testing. In all cases there was at least a four-fold rise in VDRL titres.

Group 3: Infants without congenital syphilis but with similar clinical signs at presentation: These infants presented between the ages of 0 and 4 months and demonstrated one or more of the clinical signs considered to be suggestive of congenital syphilis. ${ }^{12}$ However, on subsequent investigation the 15 cases in this category had negative treponemal and cardiolipin tests for syphilis. Other causes were found for their clinical signs.

Group 4: Well infants without congenital syphilis: There were 51 newborns and another 15 infants aged 2 weeks to 4 months in this category. The patients were regarded as being at risk for congenital syphilis because of untreated or inadequately treated maternal syphilis during pregnancy. The cases were examined at birth and, in addition to serological tests for syphilis, radiographs of the long bones were obtained. The infants were considered to be uninfected as there were no clinical features of disease and the VDRL titres had declined to zero by 3-4 months in the absence of treatment. ${ }^{14}$

Serological tests

FTA-ABS (IgM) The FTA-ABS (IgM) test was carried out according to previously described methods. ${ }^{4}$ FTA-Treponema pallidum suspension (Behring) was used to prepare antigencoated slides. The slides were fixed in $100 \%$ acetone for 10 minutes and air dried before use. Heat-inactivated serum $(10 \mu \mathrm{l})$ was diluted 1:5 in FTA absorption medium (Zeus Scientific USA). After thorough mixing, an equal volume of either normal saline or $\mathbf{R F}$ absorbent (Behring) was added to give a final serum dilution of $1: 10$. After incubation for 15 minutes at room temperature the sera treated with RF absorbent were centrifuged at $300 \mathrm{~g}$ for 10 minutes. Without disturbing the precipitate, $10 \mu \mathrm{l}$ of diluted serum was added to the slides coated with treponemes. The slides were washed with PBS ( $\mathrm{pH} \mathrm{7.6)}$ ) following incubation in a moist chamber for 3 hours at $37^{\circ} \mathrm{C}$ (this period was chosen for convenienceequivalent results were obtained with shorter times). After the slides were air dried, $10 \mu \mathrm{l}$ of fluorescein-labelled anti-human IgM (Wellcome Diagnostics) was added. The material was incubated for 40 minutes at $37^{\circ} \mathrm{C}$, washed, dried and examined for fluorescence. A Zeiss microscope with mercury vapour lamp and filter sets 09 blue (exciter filter BP 450-490, beam splitter FT 510, barrier filter LP 520) and 15 green (exciter filter BP 546-12, beam splitter FT 580, barrier filter LP590) was in use in the laboratory for FTA-IgG determination by the Zeiss double-staining method. For IgM determination the fluorescein isothiocyanate filter pack was employed and the slides were checked for the presence of spirochaetes using a darkground microscope. The FTAABS (IgM) test was carried out before and after the IgG immunoprecipitation step.

RF ELISA An ELISA to detect IgM RF was established. ${ }^{15}$ Briefly, $100 \mu$ l heat-aggregated IgG at a concentration of $0.5 \mathrm{mg} / 100 \mathrm{ml}$ was used to coat flat-bottomed microtitre plates. After overnight incubation at $4^{\circ} \mathrm{C}$, the plates were washed and blocked with $1 \%$ bovine serum albumin. Untreated sera were applied at dilutions of 1:100-1:2000 in PBS-T. After 6 washes, peroxidase-labelled goat $\mathrm{F}(\mathrm{ab})$ '2 antihuman IgM (Cappel Laboratories, Cochranville, PA) at a dilution of 1:2000 was added. Following further washing, substrate $(40 \mathrm{mM}$ $2 \cdot 2$ azinobis) was added and the optical density at $405 \mathrm{~nm}$ read after 1 hour. The ELISA was standardized with the World Health Organization reference preparation and was used to assess how complete was the removal of RF following IgG immunoprecipitation. For this purpose, $10 \mu \mathrm{l}$ of serum in $40 \mu \mathrm{l}$ PBS (pH 7.2) was mixed with $50 \mu \mathrm{l}$ of anti-human IgG. After incubation and removal of the precipitate the serum was assayed at a final dilution of $1: 200$.

IgG The IgG concentration following the treatment of the sera with anti-human IgG was measured using radial immunodiffusion plates (LC Partigen, Behring).

\section{Results}

Group 1: Infants having congenital syphilis with clinical signs at birth: The physical findings demonstrated are shown in table 1. The frequency of the various clinical manifestations was similar to that reported in other studies, ${ }^{1617}$ although hepatosplenomegaly appeared to be more common in the present study.

The RF ELISA was positive in $35 / 37$ cases. The upper limits of normal have been reported in a previous study; ${ }^{15}$ the 95 th percentile was $2.5 \mathrm{IU} / \mathrm{ml}$ in newborns aged $0-3$ days, $17.5 \mathrm{IU} / \mathrm{ml}$ between 4 days and 2 months and 
Table 1 Clinical features present in symptomatic infants

\begin{tabular}{lll}
\hline & $\begin{array}{l}\text { Patients with } \\
\text { congenital syphilis } \\
(\%)\end{array}$ & $\begin{array}{l}\text { Patients with other } \\
\text { conditions } \\
(\%)\end{array}$ \\
Clinical feature & $n=37$ & $n=15$ \\
\hline Low birth weight & 54 & 40 \\
Oedema & 40 & 7 \\
Skin rash & 51 & 33 \\
Jaundice & 30 & 13 \\
Anaemia & 24 & 13 \\
Lymphadenopathy & 5 & 0 \\
Snuffes & 8 & 0 \\
Hepatosplenomegaly & 95 & 73 \\
Pneumonitis & 19 & 0 \\
Bone changes & 86 & 60 \\
\hline
\end{tabular}

$29.5 \mathrm{IU} / \mathrm{ml}$ in infants older than 2 months but less than 4 months of age. A wide variation in RF levels amongst the symptomatic patients was apparent. Fifteen cases had RF values between 2.5 and $50 \mathrm{IU} / \mathrm{ml}$, while four patients had concentrations greater than $500 \mathrm{IU} / \mathrm{ml}$. The remainder of infants had intermediate levels.

Prior to IgG precipitation the FTA-ABS (IgM) test was reactive in 34 (92\%) cases; 33 of the 34 were also IgM RF positive. The three patients with negative FTA-ABS (IgM) tests had other strong supporting evidence of congenital syphilis. One patient was born to a mother whose VDRL titre was 256; the mother had received no therapy prior to delivery. The preterm infant had hepatosplenomegaly and haemolytic anaemia. Another infant had snuffles, periosteal reactions and the TPHA test remained positive for over a year. The remaining case had periosteal reactions, metaphyseal dysplasia and pseudoparesis in addition to having positive VDRL and TPHA tests.

IgM RF removal was complete in all but three cases-these three infants had the highest RF levels. Using the radial immunodiffusion plates, IgG was not detectable in any of the sera following the use of the anti-IgG, suggesting that RF interference was prevented. The FTA-ABS (IgM) test was positive in 29 (78\%) of cases after IgG precipitation. The five infants in whom the test became negative had all been IgM RF positive. The lower sensitivity of the FTA-ABS (IgM) test, after the step to eliminate RF interference, was not statistically significant $(p=0.19$ using the Chi-square test).

One patient with a negative RF ELISA had a nonreactive FTA-ABS (IgM) test which became positive after IgG removal.

Group 2: Infants having congenital syphilis with- out clinical signs at birth: The features leading to the diagnosis of congenital syphilis in these cases are shown in table 2 as are the RF levels. Seven patients had positive RF tests before immunoprecipitation and the FTA-ABS (IgM) test was positive in 10 of 12 cases. None of the cases had positive RF tests after the use of antiIgG but the FTA-ABS (IgM) test was reactive in only three cases. The poorer performance of the fluorescent test following RF removal was significant ( $p=0.006$ using Fisher's exact test).

Group 3: Infants without congenital syphilis but with similar clinical signs at presentation: There were nine newborns and a further six infants less than 4 months of age in this category. The clinical findings are shown in table 1 . The patients had a variety of final diagnoses, the commonest of which was septicaemia (7 cases). Escherichia coli was isolated from three of the cases, Staphylococcus aureus from one patient and Neisseria gonorrhoeae from another. In the remaining cases septicaemia was presumed from the clinical findings and the response to antibiotics. Cytomegalovirus infection occurred in five cases; the diagnosis was based on isolation of the organism from the urine in four patients and on a positive ELISA for IgM antibodies in the absence of RF in a fifth case. There was one case each of hereditary spherocytosis, congenital rubella and trisomy 13; the latter patient presented with purpura and hepatosplenomegaly and was found to have extensive extramedullary haematopoiesis.

IgM RF was initially detected in three cases. However, the ELISA for RF in these three patients became negative after IgG removal. The FTA-ABS (IgM) test was negative in all patients (before and after steps to prevent RF interference).

Group 4: Controls: Of 51 newborns, none had positive RF tests although one patient had a positive FTA-ABS (IgM) test prior to IgG extraction (table 3 ).

Four of 15 patients aged between 1 and 4 months had RF detected by ELISA. The RF was removed by IgG precipitation. The FTAABS (IgM) test was reactive in two cases prior to the use of the anti-IgG; one of these patients was $\mathrm{RF}$ positive. Both the false positive fluorescence tests were eliminated with the RF absorbent.

Table 2 The effect of RF removal on the FTA-ABS (IgM) test in infants with congenital syphilis without clinical signs at birth

\begin{tabular}{|c|c|c|c|c|c|}
\hline \multirow[b]{2}{*}{ Age at diagnosis } & \multirow[b]{2}{*}{ Features at diagnosis } & \multicolumn{2}{|c|}{ Before treatment with anti-IgG $G^{\star}$} & \multicolumn{2}{|c|}{ After treatment with anti-IgG* } \\
\hline & & RF level (IU/ml) & $F T A-A B S(I g M)$ & RF level (IU/ml) & $F T A-A B S(I g M)$ \\
\hline $\begin{array}{l}\text { Perinatal } \\
\text { Perinatal } \\
\text { Perinatal } \\
\text { Perinatal } \\
4 \text { months } \\
10 \text { weeks } \\
6 \text { weeks } \\
6 \text { weeks } \\
3 \text { months } \\
4 \text { months } \\
6 \text { weeks } \\
\text { 6weeks }\end{array}$ & $\begin{array}{l}\text { Metaphyseal dysplasia of long bones } \\
\text { Metaphyseal dysplasia of long bones } \\
\text { Metaphyseal dysplasia of long bones } \\
\text { Metaphyseal dysplasia of long bones } \\
\text { Rash, snuffes, splenomegaly, 16-fold rise in VDRL titre } \\
\text { Snuffles, HSM, 4-fold rise in VDRL titre, periosteal elevation } \\
\text { Snuffles, HSM, 4-fold rise in VDRL titre } \\
\text { Snuffles, rash, HSM, 4-fold rise in VDRL titre } \\
\text { Snuffles, rash, splenomegaly 32-fold rise in VDRL titre } \\
\text { 4-fold rise in VDRL titre } \\
\text { 4-fold rise in VDRL titre } \\
\text { 64-fold rise in VDRL titre }\end{array}$ & $\begin{array}{r}35 \\
27 \\
0 \\
15 \\
12 \\
20 \\
19 \\
3 \\
0 \\
0 \\
0 \\
0\end{array}$ & $\begin{array}{l}\text { +ve } \\
+ \text { ve } \\
+ \text { ve } \\
+ \text { ve } \\
+ \text { ve } \\
+ \text { ve } \\
+ \text { ve } \\
+ \text { ve } \\
+ \text { ve } \\
\text { - ve } \\
+ \text { ve } \\
\text { - ve }\end{array}$ & $\begin{array}{l}0 \\
0 \\
0 \\
0 \\
0 \\
0 \\
0 \\
0 \\
0 \\
0 \\
0 \\
0\end{array}$ & $\begin{array}{l}\text { + ve } \\
\text { + ve } \\
\text { - ve } \\
\text { + ve } \\
\text { - ve } \\
\text { - ve } \\
\text { - ve } \\
\text { - ve } \\
\text { - ve } \\
\text { - ve } \\
\text { - ve } \\
\text { - ve }\end{array}$ \\
\hline
\end{tabular}

* Tests performed at birth

Tests performed at birth
HSM, Hepatosplenomegaly; VDRL, Venereal Disease Research Laboratory; +ve, Positive; - ve, Negative. 
Table 3 Performance of the FTA-ABS (IgM) test before and after RF removal

\begin{tabular}{|c|c|c|c|c|}
\hline \multirow[b]{2}{*}{ Condition } & \multirow[b]{2}{*}{ Number } & \multirow[b]{2}{*}{ IgM RF positive } & \multicolumn{2}{|c|}{ FTA-ABS (IgM) positive } \\
\hline & & & Before $R F$ removal & After $R F$ removal \\
\hline $\begin{array}{l}\text { Congenital syphilis with signs } \\
\text { Congenital syphilis without signs } \\
\text { Other condition with signs } \\
\text { Newborn control } \\
\text { Control aged } 1-4 \text { months }\end{array}$ & $\begin{array}{l}37 \\
12 \\
15 \\
51 \\
15\end{array}$ & $\begin{array}{r}35 \\
7 \\
3 \\
0 \\
4\end{array}$ & $\begin{array}{r}92 \% \\
83 \% \\
0 \% \\
2 \% \\
13 \%\end{array}$ & $\begin{array}{r}78 \% \\
25 \% \\
0 \% \\
0 \% \\
0 \%\end{array}$ \\
\hline
\end{tabular}

\section{Discussion}

The immunoprecipitation method of preventing $R F$ interference appeared to be simple and effective. IgM RF was not detected by ELISA in $89 \%$ of treated sera, in keeping with results in patients with rheumatoid arthritis. ${ }^{11}$ In the present study, sera contained no IgG after use of the RF absorbent, indicating that $R F$ interference could not occur. ${ }^{10}$

The sensitivity of the FTA-ABS (IgM) in symptomatic patients (Group 1) was not significantly reduced by RF removal. However, tests in five patients became negative after eliminating the effect of RF, suggesting that RF was responsible for the positive tests. ${ }^{18}$

One patient whose serum tested negative for RF had a positive FTA-ABS (IgM) test after IgG precipitation. This phenomenon could have been due to competitive inhibition between IgM and IgG treponemal antibodies. IgG extraction would then have removed the competition for binding sites. ${ }^{19}$

Steps to remove IgG from the sera could, therefore, have had different effects on the sensitivity of the FTA-ABS (IgM) test in different patients. The sensitivity of the test after RF removal in the symptomatic patients in the present study (78\%) was lower than the 96-100\% reported in various other studies in which RF was not extracted. ${ }^{520}$

In the infants with congenital syphilis who had no clinical signs at birth (Group 2), the sensitivity of the FTA-ABS (IgM) test was significantly reduced by $\mathrm{RF}$ extraction. It has been shown that infants with congenital syphilis produce relatively large amounts of IgM RF and less IgM directed against $T$ pallidum, that is, less specific IgM. ${ }^{6}$ This may be particularly true in asymptomatic patients who have less advanced disease, as nonspecific IgM (eg RF) is found before specific IgM. ${ }^{21}$

As a result of this, RF removal should have a greater effect on the sensitivity of the FTAABS (IgM) test in asymptomatic than in symptomatic patients who generally have more advanced disease. In the latter group the FTAABS (IgM) test would be more likely to be positive due to specific IgM; extraction of RF would not alter this result.

The presence of RF alone does not explain the positive FTA-ABS (IgM) tests before IgG removal in all cases. There were two patients in Group 2 (that is, infants without signs at birth) with negative RF tests. The FTA-ABS (IgM) tests were initially positive but became negative after immunoprecipitation. Thus antiglobulins could not have caused the positive FTA-ABS (IgM) results unless hidden RF was present. ${ }^{22}$ Tests to detect hidden RF, however, were negative (results not shown). An alternative explanation is that precipitation of the $\operatorname{IgG} \stackrel{\mathbb{8}}{\circ}$ resulted in a loss of immune complexes containing specific IgM.

The specificity of the FTA-ABS (IgM) test was investigated in groups 3 and 4 . In order for IgM RF to be detected as specific IgM both anti-treponemal IgG and RF must be present. ${ }^{18}$ How likely is this combination in practice? The commonest reason for symptomatic $\bar{O}$ infants to have RF in the serum (apart from $\overrightarrow{\vec{H}}$ congenital syphilis) is probably CMV infection. Given that $42 \%$ of infants with $\mathrm{CMV} \stackrel{\text { ? }}{=}$ produce $\mathrm{RF}^{23}$ and, that in the population studied, $8 \%$ of expectant women have positive + treponemal tests for IgG, ${ }^{24}$ false positive FTA- is ABS (IgM) tests would occur in $3.4 \%$ of symptomatic cases. This low figure seems to be borne out in the present study where there were no false positive results amongst 15 으 symptomatic patients.

The specificity of the FTA-ABS (IgM) test in newborns in group 4 was high regardless of whether or not IgG was removed. In contrast, in uninfected infants outside the neonatal period, a higher incidence of false positives (13\%) was found prior to IgG removal. A possible explanation for this is that RF is more likely to be present in these older patients due to the production of antiglobulin to maternal IgG. $^{6815}$

There were two cases with falsely positive FTA-ABS (IgM) tests without demonstrable on RF. Hidden RF or a deficiency of conjugate specificity may have played a role as the tests became negative after precipitation of the 8 IgG.

These findings have a number of implica- 은 tions. In newborn infants the prevention of RF interference reduced the sensitivity of the FTA-ABS (IgM) test, particularly in the of asymptomatic cases. It seems important not to extract RF using immunoprecipitation in these patients.

A low incidence of false positive FTA-ABS (IgM) tests $(2 \%)$ was found amongst high-risk newborns (Group 4) and false positives were not seen amongst a group of infants with 0 clinical signs who did not have congenital syphilis (even though some had positive RF tests). Prevention of RF interference did not $\stackrel{\mathbb{D}}{\circ}$ seem to be of value in this group either.

The older high-risk infants had a greater incidence of false positive FTA-ABS (IgM) tests if the RF was not removed. In this age group, however, infected infants would be? likely to display physical signs and other tests such as radiography and cardiolipin antibody titres would be more useful than in newborns, so that the higher false positive rate may be acceptable. 
The findings suggest that, in the population tested, it is immaterial whether the FTA-ABS (IgM) test is positive due to the presence of specific IgM or IgM RF. In both instances the patient is likely to have congenital syphilis and the original fluorescent test is simpler, which is an advantage in underdeveloped countries. Hence it seems advisable not to use the immunoprecipitation method to prevent RF interference, particularly when testing newborns from communities where follow-up is difficult and there is a high incidence of syphilis.

We thank A F Malan and D W Beatty for helpful suggestions Financial support was obtained from the Cooper-Lowveld Fund of the University of Cape Town, the Mobil Research Associateship of the Institute of Child Health and the Medical Research Council of South Africa.

1 Schulz KF, Cates W Jr, O'Mara PR. Pregnancy loss, infant death, and suffering: legacy of syphilis and gonorrhoea in death, and suffering: legacy of syphilis and

2 Sanchez PJ, McCracken GH Jr, Wendel GD, Olsen K, Threlkeld N, Norgard MV. Molecular analysis of the fetal IgM response to Treponema pallidum antigens: implications for improved serodiagnosis of congenital syphilis. $f$ Infect Dis 1989;159:508-17.

3 Rathbun KC. Congenital syphilis: a proposal for improved surveillance, diagnosis and treatment. Sex Transm Dis 1983;10:102-7.

4 Scotti AT, Logan L. A specific IgM antibody test in neonatal congenital syphilis. $\mathcal{f}$ Pediatr 1968;73:242-3.

5 Kaufman RE, Olansky DC, Wiesner PJ . The FTA-ABS (IgM) test for neonatal congenital syphilis: a critical review. $\mathcal{F}$ American Venereal Disease Association 1974; 1:79-84.

6 Reimer CB, Black CM, Phillips DJ, et al. The specificity of fetal IgM. Antibody or anti-antibody? Ann NY Acad Sci fetal IgM. Antibody

7 Meyer MP, Malan AF. Rheumatoid factor in the diagnosis of congenital syphilis. S Afr Med $\mathcal{f}$ 1987;72:668-9.

8 Stagno S, Pass RF, Reynolds DW, Moore MA, Nahmias AJ, Alford CA. Comparative study of diagnostic procedures for congenital cytomegalovirus infection. Pediatrics 1980:65:251-7.
9 Hyde B, Barnett EV, Remington JS. Method for differentiation of nonspecific from specific toxoplasma IgM
fluorescent antibodies in patients with rheumatoid factor. fluorescent antibodies in patients with rhe
Proc Soc Exp Biol Med 1975;148:1184-8.

10 Gispen R, Nagel J, Brand-Saathof B, De Graaf S. Immunofluorescence test for IgM rubella antibodies in whole serum after absorption with anti-gamma Fc. Clin Exp Immunol 1975;22:431-7.

11 Cerny EH, Farshy CE, Hunter EF, Larsen SA. Rheumatoid factor in syphilis. $\mathcal{f}$ Clin Microbiol 1985;22:89-94.

12 Kaufman RE, Jones OG, Blount JH, Wiesner PJ. Questionnaire survey of reported early congenital syphilis. Problems in diagnosis, prevention and treatment. Sex Transm Dis 1977;4:135-9.

13 Meyer MP, Malan AF. Rheumatoid factor in congenital syphilis. Genitourin Med 1989;65:304-7.

14 Johnston NA. Neonatal congenital syphilis: diagnosis by the absorbed fluorescent treponemal antibody (IgM) test. $\mathrm{Br}$ IVener Dis 1972;48:464-9.

15 Meyer MP, Beatty DW. IgM rheumatoid factor in congenital syphilis-associations with clinical and laboratory findings. Clin Exp Immunol 1991;86:43-8.

16 Chawla V, Pandit PB, Nkrumah FK. Congenital syphilis in the newborn. Arch Dis Child 1988;63:1393-4.

17 Malan AF. Special infections in the newborn (syphilis, tetanus, tuberculosis). In: Stern L, Vert P, eds. Neonatal medicine. New York: Masson, 1987:628.

18 Shirodaria PV, Fraser KB, Stanford F. Secondary fluorescent staining of virus antigens by rheumatoid factor and fluorescein-conjugated anti-IgM. Ann Rheum Dis 1973;32:53-7.

19 Cohen IR, Norins LC, Julian AJ. Competition between, and effectiveness of, IgG and IgM antibodies in indirect fluorescent antibody and other tests. $f$ Immunol 1967;98:143-9.

20 Rosen EU, Richardson NJ. A reappraisal of the value of the IgM fluorescent treponemal antibody absorption test in the diagnosis of congenital syphilis. $\mathcal{f}$ Pediatr $1975 ; 87: 38-42$.

21 Alford CA Jr, Polt SS, Cassady GE, Straumfiord JV, Remington JS. Gamma M-fluorescent treponemal antibody in the diagnosis of congenital syphilis. $N$ Eng $7 \mathrm{Med}$ 1969;280:1086-91.

22 Allen JC, Kunkel HG. Hidden rheumatoid factors with specificity for native gamma globulins. Arthritis Rheum specificity for n.

23 Griffiths PD, Stagno S, Pass RF, Smith RJ, Alford CA Congenital cytomegalovirus infection: diagnostic and prognostic significance of the detection of specific prognostic significance of the detection of specific immunoglobulin

24 Gonin JM. Syphilis-an appraisal of the Groote Schuur Hospital antenatal screening programme. S Afr Med $\mathcal{J}$ 1985;67:962-5. 